\title{
ELECTROCARDIOGRAPHIC CHANGES IN SUBARACHNOID HÆMORRHAGE, MENINGITIS, AND INTRACRANIAL SPACE-OCCUPYING LESIONS
}

\author{
BY \\ COLIN HERSCH \\ From the Department of Medicine, Baragwanath Hospital, Johannesburg, South Africa \\ Received October 28, 1963
}

Little attention has been given to the electrocardiographic abnormalities associated with diseases of the brain and meninges. Most work on this subject has been directed to cases with subarachnoid hæmorrhage, whereas only isolated reports dealing with meningitis or intracranial space-occupying lesions have appeared. Best known of the abnormalities seen in cases of subarachnoid hæmorrhage are those simulating ischæmic heart disease (Shuster, 1960; Cropp and Manning, 1960; Beard, Robertson, and Robertson, 1959; Levine, 1953).

The purpose of this study is to record and compare the electrocardiographic abnormalities observed in patients with subarachnoid hæmorrhage, meningitis, and intracranial space-occupying lesions. An attempt has been made to determine whether these changes are specific for each of these conditions, or whether there is a pattern common to diseases of the brain and meninges. Furthermore, the level of consciousness has been correlated with the electrocardiographic abnormalities.

\section{SubJeCtS AND MeThods}

During the years 1958 to 1961 , 60 Bantu patients with cerebral diseases were studied at Baragwanath Hospital. They were divided into three groups.

There were 20 patients with subarachnoid hæmorrhage, proven on lumbar puncture. Of these, 12 were men and 8 were women. Their ages ranged between 16 and 40 years, with a mean age of 29 years. The site and origin of the subarachnoid hæmorrhage could be determined in only 7 of them.

The second group consisted of 20 patients with pyococcal meningitis, of which 10 were meningococcal and 7 were pneumococcal. In 3 no organisms could be isolated from the cerebrospinal fluid. In this group there were 17 men and 3 women. Their ages varied between 20 and 36 years, with a mean age of 26 years.

The third group comprised 20 patients with varying types of intracranial space-occupying lesions, of whom 15 were men and 5 were women. Their ages varied between 20 and 45 years, with a mean age of 31 years. Cerebral tumours were present in 11, subdural hæmatomata in 3, cerebral abscesses in 3, parasitic cysts in 2, and a tuberculoma in the remaining one. In this group the parietal lobe was affected in 9 patients, the frontal lobe in 3, the temporal lobe in 2 , and the brain-stem in 2 . The remaining patients had lesions in the pituitary gland, cerebellum, basal ganglia, and the right cerebral hemisphere.

All patients with disease of the cardiovascular system, as determined clinically and at necropsy, were excluded from this study. Electrocardiographic tracings were obtained within 24 hours of admission from cases with subarachnoid hæmorrhage and meningitis, and at the time of diagnosis in the patients with intracranial space-occupying lesions. Estimations of the blood urea, $\mathrm{CO}_{2}$ combining power, and electrolytes were made simultaneously with the electrocardiograms in 54 of the 60 patients. The cerebrospinal fluid pressure was measured in 15 with subarachnoid hæmorrhage, in 15 with meningitis, and in 17 with intracranial space-occupying lesions. 
TABLE I

Incidence of Cardiographic Abnormalities in Various Cerebral Diseases and in Controls

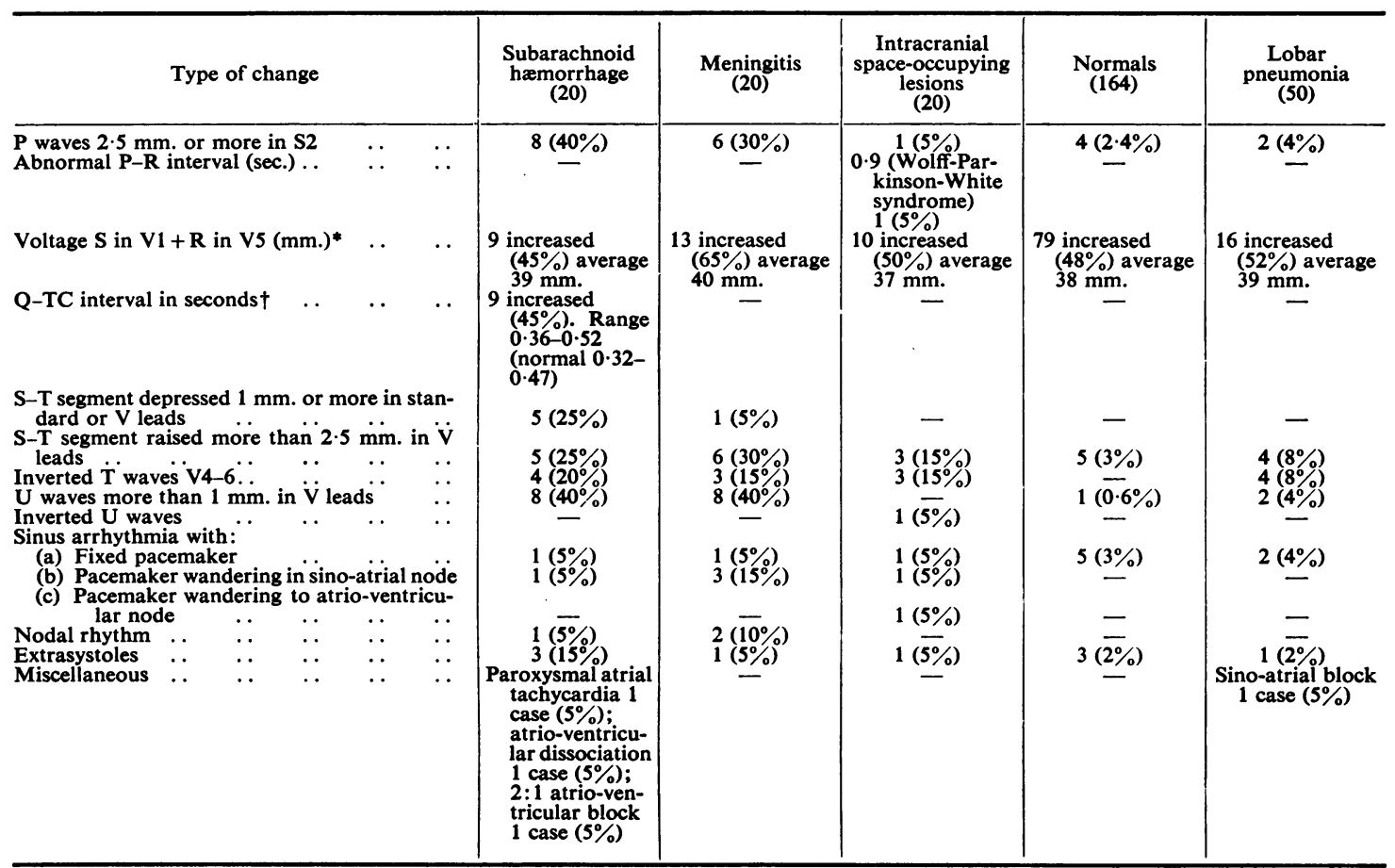

* Increased voltage: SV1 + RV5>35 mm. (Sokolow and Lyon, 1949).

Note that 48 per cent of normal Bantu have increased QRS voltage by standards established for white subjects.

† Q-TC measured by the method of Ashman and Hull (1941).

All the patients were classified into three groups on the basis of their level of consciousness at the time when their electrocardiograms were recorded. Those in Group A were fully conscious, those in Group B were confused, drowsy, or stuporous, and all in Group C were in coma.

To obtain the average number of electrocardiographic abnormalities per patient for each group, one point was recorded for each significant abnormality (as listed in Table I) and the total was then divided by the number of patients in each group.

There were 2 control groups: 164 healthy Bantu subjects and 50 patients with lobar pneumonia. The latter group was chosen to exclude the possible electrocardiographic effects of fever, tachycardia, septicæmia, and toxæmia, in cases with meningitis. The age and sex distribution was approximately equal in both these groups.

Serial electrocardiograms were performed at variable intervals in 7 patients with subarachnoid hæmorrhage, 5 with meningitis, and in one with an intracranial space-occupying lesion.

\section{RESULTS}

The electrocardiographic findings are summarized in Table I.

$P$ Waves of $2.5 \mathrm{~mm}$. or More in Standard Lead 2 (Fig. 1 and 3). These were seen in $8(40 \%)$ patients with subarachnoid hæmorrhage, $6(30 \%)$ with meningitis, $1(5 \%)$ with an intracranial spaceoccupying lesion, $2(4 \%)$ with lobar pneumonia, and in $4(2.4 \%)$ healthy controls. The difference was only statistically significant when comparing the patients with subarachnoid hæmorrhage with those with intracranial space-occupying lesions and controls $(\mathrm{p}<0.05)$.

$Q R S$ Voltage. The number of patients with increased QRS voltage was similar in the 3 groups studied and in the controls. 


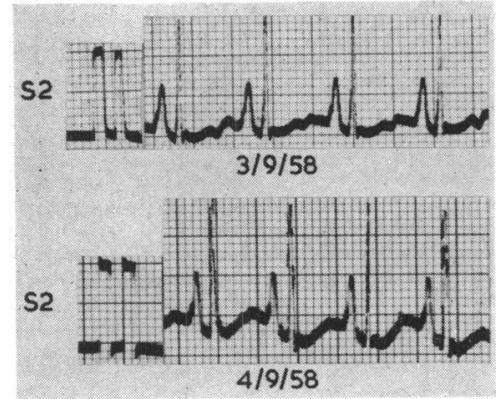

FIG. 1.-P waves of 6 to $7 \mathrm{~mm}$. in height in lead II.

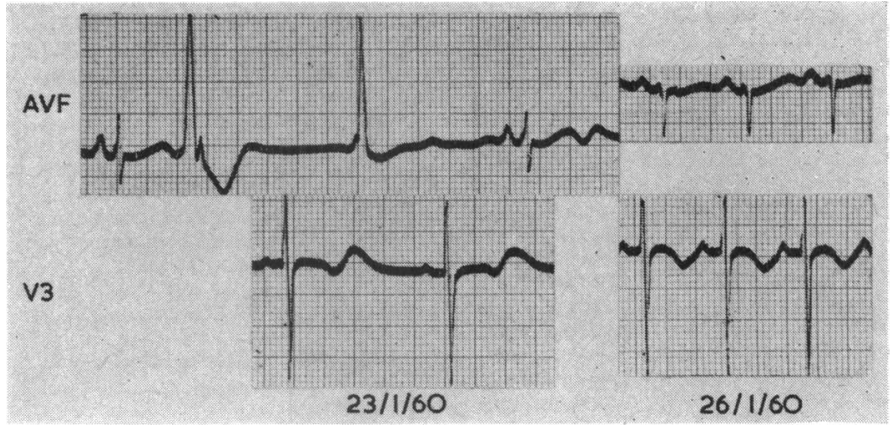

FIG. 2.-On 23/1/60 lead AVF shows an atrial ectopic beat with aberrant ventricular conduction, followed by a ventricular ectopic beat, nodal escape and another similar auricular ectopic beat. Inverted $\mathrm{T}$ waves are seen in $\mathrm{V} 3$ and abnormal $U$ waves in leads AVF and V3 (serum K $3.0 \mathrm{mEq} / \mathrm{l}$.). In the tracing three days later, the arrhythmia has disappeared, the $\mathrm{T}$ waves in V3 are inverted, but the heart rate is too fast to assess $U$ waves (serum $\mathrm{K} 4.0 \mathrm{mEq} / \mathrm{l}$.).

Increased Q-TC Interval. This was present in $9(45 \%)$ patients with subarachnoid hæmorrhage, but was not found in the remaining 2 groups or in the controls. This finding was statistically significant $(\mathrm{p}<0.05)$.

Depression of the $S-T$ Segment of $1 \mathrm{~mm}$. or more in Standard or Pracordial Leads. This was found in $5(25 \%)$ patients with subarachnoid hæmorrhage and in $1(5 \%)$ with meningitis, but not in those with intracranial space-occupying lesions or the controls. The difference was statistically significant only when comparing subarachnoid hæmorrhage with intracranial space-occupying lesions and the controls $(\mathrm{p}<0.05)$. Of the 20 patients with subarachnoid hæmorrhage, $9(45 \%)$

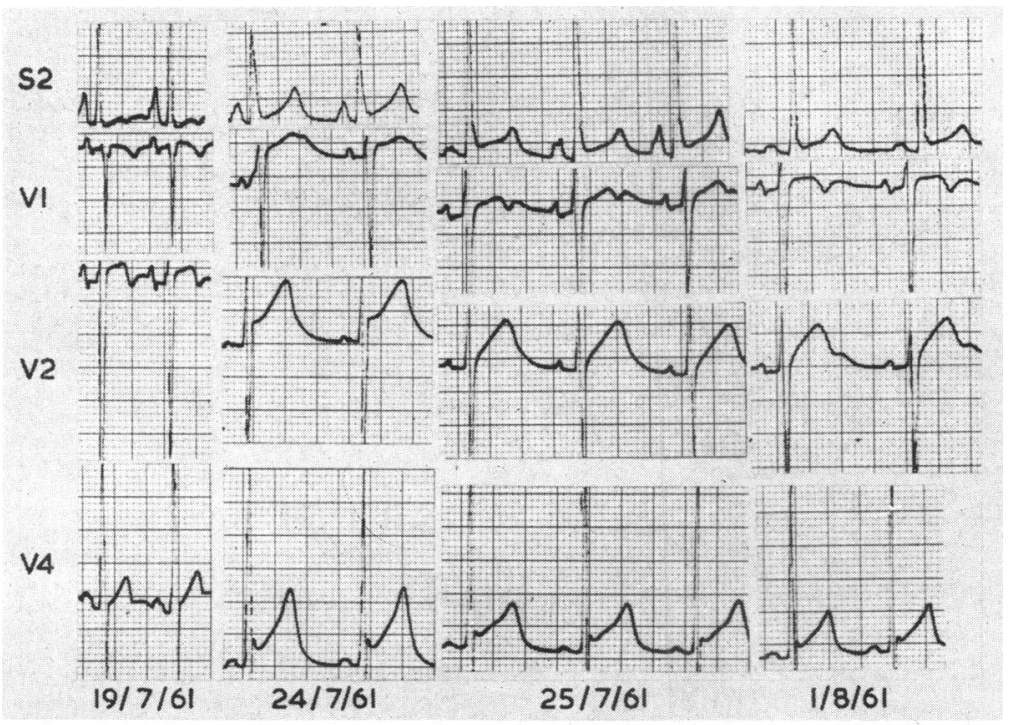

Fig. 3.- Lead II on $19 / 7 / 61$ shows tall $P$ waves. On $25 / 7 / 61$ the pacemaker is wandering in the sino-atrial node. In the two remaining tracings, the $\mathbf{P}$ waves are different in form. Prominent $U$ waves are seen in $V 1$ on 24/7/61 and 25/7/61, and in V2 on 1/8/61. Raised S-T segments are seen in all leads of the follow-up electrocardiograms. 


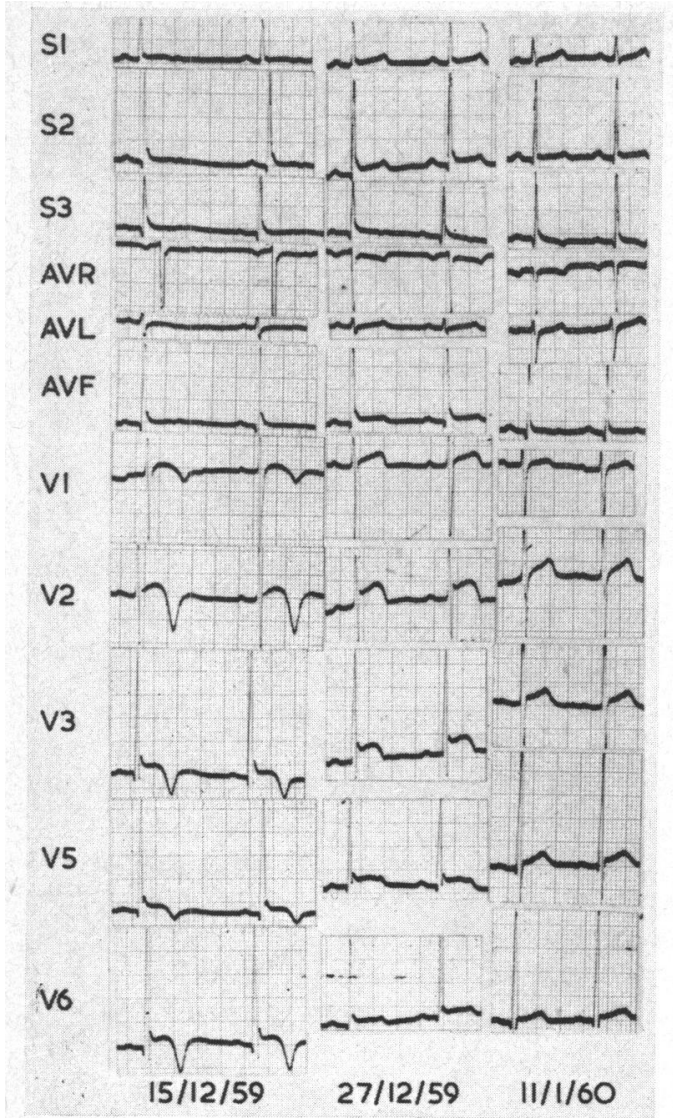

FIG. 4.-On 15/12/59 the $T$ waves are of low voltage in the standard and unipolar limb leads and inverted in all leads; the S-T segments are raised over left ventricular surface leads. On $27 / 12 / 59$ the $T$ waves are tending towards normal but the S-T segments remained raised. Except for slight $\mathrm{S}-\mathrm{T}$ segment elevation, the tracing on $11 / 1 / 60$ is normal. died, whereas there were $4(80 \%)$ deaths amongst the 5 patients with subarachnoid hæmorrhage showing S-T segment depression.

$S-T$ Segments Raised more than $2.5 \mathrm{~mm}$. in Pracordial Leads (Fig. 3 and 4). These were noted in $5(25 \%)$ patients with subarachnoid hæmorrhage, $6(30 \%)$ with meningitis, $3(15 \%)$ with intracranial space-occupying lesions, $4(8 \%)$ with lobar pneumonia, and $5(3 \%)$ normal controls. The groups with subarachnoid hæmorrhage and meningitis differed significantly from the controls $(\mathrm{p}<0.05)$, but the groups with cerebral disease did not differ significantly from each other.

Inverted $T$ Waves in V4 to V6 (Fig. 4). The number of patients with this abnormality in the groups with subarachnoid hæmorrhage, meningitis, and intracranial space-occupying lesions were $4(20 \%), 3(15 \%)$, and $3(15 \%)$ respectively as compared to none in the normal controls and 4 $(8 \%)$ in the group with lobar pneumonia. These findings were not statistically significant.

$U$ Waves of $1 \mathrm{~mm}$. or more in Pracordial Leads (Fig. 2 and 3). These were found in $8(40 \%)$ patients with subarachnoid hæmorrhage and 8 $(40 \%)$ with meningitis as compared to none with intracranial space-occupying lesions, $2(4 \%)$ with pneumonia, and $1(0.6 \%)$ of the healthy controls. This abnormality was therefore significant when patients with subarachnoid hæmorrhage and meningitis were compared with the remaining groups $(\mathrm{p}<0.05)$.

Arrhythmias. No conclusion could be drawn as to the relative incidences of arrhythmias in this study as too few cases were recorded (Fig. 2 and 3).

Serial Electrocardiograms. Table II shows the duration of the electrocardiographic abnormalities in 13 patients where serial tracings were made. These varied from 1 to 27 days.

Electrocardiographic Abnormalities at Various Levels of Consciousness. The average number of electrocardiographic abnormalities per patient was 1.1 in group A, 1.6 in group B, and 2.3 in group C.

Serum Electrolyte Disturbances. These were commonly found in all 3 groups. The commonest abnormalities in decreasing order of frequency were respiratory alkalosis, hyponatræmia, hypochloræmia, hypokalæmia, and hyperchloræmia. Only hypokalæmia could be correlated with the electrocardiographic findings.

Hypokalæmia was observed in 10 patients with subarachnoid hæmorrhage, 3 with intracranial space-occupying lesions but not in those with meningitis. Electrocardiographic appearances typical of hypokalæmia are S-T segment depression, abnormal U waves, Q-TC interval prolongation, and arrhythmias. In this study the finding of two or more of these changes was taken to indicate electrocardiographic evidence of hypokalæmia. Of the 10 patients in whom subarachnoid hæmorrhage was associated with hypokalæmia, 5 had two or more of these electrocardiographic 
TABLE II

Duration of Electrocardiographic AbNormalities

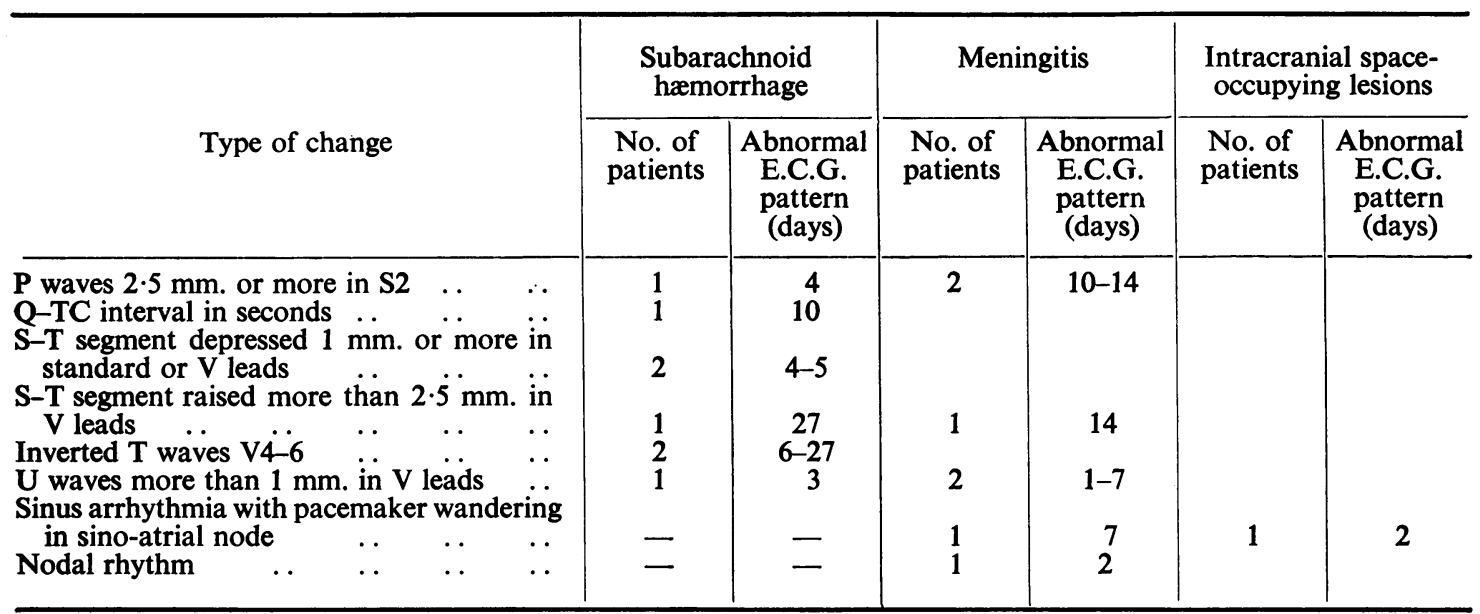

Note that one patient with subarachnoid hæmorrhage and two with meningitis showed more than one abnormality.

features, whereas the 3 with intracranial space-occupying lesions associated with hypokalæmia had normal electrocardiograms. The remaining cases of subarachnoid hæmorrhage with normal serum potassiums and those with meningitis and intracranial space-occupying lesions, all had less than two of these changes. In the patients with subarachnoid hæmorrhage, hypokalæmia was present in 5 of 9 with increased Q-TC intervals, 4 of 5 with depressed S-T segments, 4 of 8 with abnormally tall $U$ waves, and in all 4 patients with arrhythmias.

Cerebrospinal Fluid Pressure. Papillœdema or pressures of $300 \mathrm{~mm}$. of water were found in 6 of 15 patients with subarachnoid hæmorrhage, 5 of 15 with meningitis, and in 10 of 17 with intracranial space-occupying lesions.

\section{Discussion}

Tall $P$ and $U$ waves were commonly noted in patients with subarachnoid hæmorrhage and meningitis in this series. $\mathbf{P}$ waves of increased amplitude have not previously been observed in patients with subarachnoid hæmorrhage, meningitis, or space-occupying lesions, but abnormal U waves have frequently been noted in subarachnoid hæmorrhage (Burch, Meyers, and Abildskov, 1954; Marks, 1956; Shuster, 1960; Cropp and Manning, 1960) and occasionally in intracranial space-occupying lesions (Hegglin and Holzmann, 1937).

Whereas raised S-T segments occurred more commonly with subarachnoid hæmorrhage and meningitis than with intracranial space-occupying lesions, $\mathrm{T}$-wave inversion was common to all groups with intracerebral pathology. Shuster (1960), Cropp and Manning (1960), and Levine (1953) have all stressed displacement of S-T segments and T-wave inversion, suggestive of recent myocardial injury, as the most significant finding in cases with subarachnoid hæmorrhage. Of particular interest is the patient described by Beard et al. (1959), who presented with chest pain but no clinical signs and symptoms of subarachnoid hæmorrhage. An erroneous diagnosis of myocardial infarction was made because of typical electrocardiograms. At necropsy there was a ruptured aneurysm arising from the internal carotid artery and subarachnoid hæmorrhage; the coronary arteries and myocardium were healthy. Elevation of the S-T segment and inversion of the T wave have previously been noted in meningitis (Tobin, 1956), but not in intracranial space-occupying lesions.

Depression of S-T segments has been reported in subarachnoid hæmorrhage (Cropp and Manning, 1960; Shuster, 1960), meningitis (Lepeschkin, 1951), cerebral tumours (Paulian, Tudor, 
and Constantinesco, 1939; Aschenbrenner and Bodechtel, 1938), and during manipulation of the circle of Willis under hypothermia and light anæsthesia (Pool, 1957). In this series, S-T segment depression was of poor prognostic significance in cases of subarachnoid hæmorrhage, as 80 per cent of such patients died. The one with meningitis, showing S-T segment depression, recovered.

In the present study, prolongation of the Q-TC interval was confined to cases with subarachnoid hæmorrhage, but occasional instances of this abnormality have been reported in meningitis (Tobin, 1956). Cropp and Manning (1960) reported an increased Q-TC interval in two-thirds of 29 cases with subarachnoid hæmorrhage, which is a somewhat higher incidence than that reported here. Shuster (1960) on the other hand, found 12 patients with subarachnoid hæmorrhage who had short Q-TC intervals. The finding of a prolonged Q-TC interval in subarachnoid hæmorrhage accords with previous observations in head injuries (Hersch, 1961), in which the Q-TC interval was increased in 15 per cent, the common factor possibly being the subarachnoid hæmorrhage, but unfortunately lumbar punctures were not performed. Burch et al. (1954) questioned the prolonged Q-T interval occurring in cerebral and subarachnoid hæmorrhage, as possibly being a Q-U interval. The difficulties of measuring the Q-T interval are well known, but Lepeschkin (1955) has described a method of differentiating a Q-T from a Q-U interval.

There were only a few examples of arrhythmia. Sinus arrhythmia with fixed and wandering pacemakers and extrasystoles were noted in all 3 groups, but nodal rhythm only occurred in association with subarachnoid hæmorrhage and meningitis. 2:1 atrio-ventricular block, atrio-ventricular dissociation, and paroxysmal atrial tachycardia were confined to single instances with subarachnoid hæmorrhage. Extrasystoles (Marks, 1956; Tobin, 1956; Aschenbrenner and Bodechtel, 1938) and wandering of the pacemaker (Cropp and Manning, 1960; Tobin, 1956; Aschenbrenner and Bodechtel, 1938) have been reported in all 3 groups, whereas atrio-ventricular dissociation (Schubart, Marriott, and Gorten, 1958), nodal rhythm (Cropp and Manning, 1960), and atrial fibrillation (Marks, 1956; Shuster, 1960) have only been described in cases with subarachnoid hæmorrhage.

The average number of electrocardiographic abnormalities per patient, in the present study, increased as the level of consciousness deteriorated. There was, however, no correlation between the type of electrocardiographic change and the level of consciousness.

\section{Mechanism of Production of Electrocardiographic Changes}

Autonomic Stimulation in the Brain. Intracranial stimulation of the sympathetic nervous system may occur in the cortex, particularly in the motor and premotor regions, in the posterior hypothalamus, midbrain, pons, medulla, and in the connexion between these areas. The main cortical representation of the parasympathetic nervous system is in area 13, which lies on the orbital surface of the frontal lobes and has a relay station in the anterior hypothalamus, with connexions in the mid-brain, pons, and medulla. Vessels of the circle of Willis have an autonomic innervation from the glossopharyngeal and vagus nerves and from a continuation of the cervical sympathetic nerves. Pool (1957) believes that stimuli applied to the circle of Willis are more likely to cause electrocardiographic abnormalities than when applied to cortical vessels and cranial nerves other than IX and $X$.

Barger, Liebowitz, and Herd (1961) showed that electrocardiographic abnormalities could be produced by infusions of epinephrine and norepinephrine into a coronary artery of an unanæsthetized dog in the absence of a rise in lactic dehydrogenase. This suggested that adrenergic reflexes could produce electrocardiographic changes without myocardial damage.

Tall $P$ waves, extrasystoles, and prolongation of the Q-TC interval have been associated with sympathetic stimulation, whereas sinus arrhythmia with a fixed or wandering pacemaker and nodal rhythm have been attributed to vagal stimulation.

Tall $\mathbf{P}$ waves are known to be caused by sympathetic stimulation as they result from exercise (Rosnowski, 1937), anxiety (Sensenbach, 1946), hypoxia (Borgard, 1936), and following the administration of adrenaline (Lepeschkin, 1951). They have also been noted in head injuries and in trauma not involving the head or chest (Hersch, 1961). Tall P waves were found in some subjects 
with normal heart rates in the present study; therefore factors other than sympathetic stimulation must have played a part. Sympathetic stimulation may have been concerned in producing the prolonged Q-TC intervals in certain instances, but of the 9 patients in whom this was found, only 3 had heart rates over 90 a minute. Injection of epinephrine in man results in a prolongation of the Q-TC interval (Hecht and Anderson, 1947). Shuster (1960) attributed the S-T depression in his cases with subarachnoid hæmorrhage to vagal stimulation, as intravenous atropine in one case caused the S-T segment to become more isoelectric, in the absence of a change in heart rate. Extrasystoles have been produced experimentally by stimulating the posterior hypothalamus in anæsthetized cats (Beattie, Brow, and Long, 1930). Storm van Leeuwen (1945) observed nodal rhythm, shift of the sino-atrial pacemaker, and multifocal extrasystoles, on stimulating the brains of cats between the posterior corpora quadrigemina and the posterior portions of the cerebellum.

In only 7 patients with subarachnoid hæmorrhage in the present study was an aneurysm or intracerebral hæmorrhage localized on angiography or at necropsy. It was therefore impossible to correlate the electrocardiographic abnormalities with the anatomical lesions. Stimulation of autonomic nerves supplying the circle of Willis, brain damage due to blood, and ischæmia from spasm of deep perforating vessels, may have contributed to the abnormal electrocardiograms in patients with subarachnoid hæmorrhage. Vasocardiac reflexes arising in the circle of Willis and diffuse cerebral dysfunction were possible factors which caused the electrocardiographic changes in patients with meningitis. In the group with intracranial space-occupying lesions, autonomic stimulation could have occurred over a wide area. It is therefore surprising that such a low incidence of electrocardiographic abnormalities was recorded here. The reason for this may have been related to the length of the illness, during which time adaptation to the lesions may have taken place.

Increased Intracranial Pressure. The electrocardiographic changes were clearly not related to the cerebrospinal fluid pressure, as pressures over $300 \mathrm{~mm}$. of water or papillodema were noted in about two-thirds of cases with intracranial space-occupying lesions, in which group the lowest number of abnormal tracings were found. Increased Q-TC intervals might have been expected in the group with the highest cerebrospinal fluid pressures, as it has been noted that increased intracranial pressure may cause an increased Q-TC interval (Hegglin and Holzmann, 1937). This abnormality, however, was confined to cases with subarachnoid hæmorrhage.

Electrolyte Disturbances. Hyperchloræmia, hypernatræmia (Allott, 1939), hypochloræmia, hyponatræmia (Welt et al., 1952), and respiratory alkalosis have all been described in brain injury, but reference to associated hypokalæmia could not be found. The cause for the low serum potassiums in these cases was not apparent. There was no correlation between the electrocardiographic changes and hyperchloræmia, hypochloræmia, hyponatræmia, and respiratory alkalosis in this study. In dogs, metabolic alkalosis and hypernatræmia produced electrocardiographic changes similar to those seen with hypokalæmia, but respiratory alkalosis had no effect on the tracings (Magida and Roberts, 1953).

In patients with subarachnoid hæmorrhage associated with hypokalæmia, 50 per cent showed two or more features suggestive of hypokalæmia on their electrocardiograms. In contrast, were the remaining patients with subarachnoid hæmorrhage with normal serum potassiums, all of whom had less than two of these features. Hypokalæmia therefore seemed to be important in the causation of abnormal electrocardiograms when these occurred in subarachnoid hæmorrhage.

Stimulation of the Myocardium by Aldosterone. A direct digitalis-like action on the myocardium by aldosterone has been postulated by Ballard and Sayers (1957). The secretion of this hormone is probably controlled by higher nervous centres, the exact site of which has not been located (Farrell, 1960).

\section{CONCLUSIONS}

It seems likely that the abnormal electrocardiograms seen particularly in cases with subarachnoid hæmorrhage and meningitis result from a combination of factors. These are hypokalæmia 
and stimulation of the autonomic nervous system in the circle of Willis, in brain centres, relay stations, and connexions, and via the media of pain, fear, and anxiety. The latter is suggested as limb trauma alone may be responsible for electrocardiographic abnormalities similar to some of those noted in this series (Hersch, 1961).

\section{SUMMARY}

Three groups of Bantu subjects, each comprising 20 cases, with subarachnoid hæmorrhage, meningitis, and intracranial space-occupying lesions, were studied with reference to their electrocardiograms. There were two control groups: 164 normal Bantu subjects and 50 Bantu patients with lobar pneumonia. The latter served as controls for the group with meningitis, in order to exclude the possible electrocardiographic effects of infection.

An increased Q-TC interval occurred only in patients with subarachnoid hæmorrhage and was recorded in 45 per cent of these. Depression of S-T segments was virtually confined to the same group.

A high incidence of tall $P$ and $U$ waves and raised S-T segments was seen in the groups with subarachnoid hæmorrhage and meningitis, whereas $\mathrm{T}$-wave inversion was commonly seen with subarachnoid hæmorrhage, meningitis, and intracranial space-occupying lesions.

The incidence of electrocardiographic changes in the group with intracranial space-occupying lesions was not statistically significant when compared with normal controls.

Causes for the electrocardiographic abnormalities are discussed.

The number of electrocardiographic abnormalities increased with deterioration in the level of consciousness.

I would like to thank Dr. M. H. Shnier and Dr. H. C. Seftel for their help with the manuscript, Professor J. E. Kerrich for the statistical analyses, Mr. A. M. Shevitz for the photographs, and Dr. I. Frack for permission to publish.

\section{REFERENCES}

Allott, E. N. (1939). Sodium and chloride retention without renal disease. Lancet, 1, 1035.

Aschenbrenner, R., and Bodechtel, G. (1938). UUber EKG.-Veränderungen bei Hirntumorkranken. Klin. Wschr., 17, 298.

Ashman, R., and Hull, E. (1941). Essentials of Electrocardiography, 2nd ed. Macmillan, New York.

Ballard, K. W., and Sayers, G. (1957). Stimulating effect of aldosterone and cortisol on the work of the isolated rat heart-lung. Abstract presented to the forty-first annual meeting of the Endocrine Society, 1957.

Barger, A. C., Liebowitz, M. R., and Herd, J. A. (1961). Chronic catheterization of the coronary artery: infusion of autonomic drugs in the unanesthetized dog. Fed. Proc., 20, 101.

Beard, E. F., Robertson, J. W., and Robertson, R. C. L. (1959). Spontaneous subarachnoid hemorrhage simulating acute myocardial infarction. Amer. Heart $J ., 58,755$.

Beattie, J., Brow, G. R., and Long, C. N. H. (1930). Physiological and anatomical evidence for the existence of nerve tracts connecting the hypothalamus with spinal sympathetic centres. Proc. roy. Soc. B, $106,253$.

Borgard, W. (1936). Ergebnisse elektrokardiographischer Untersuchungen bei Erniedrigung des atmosphärischen Druckes. Arbeitsphysiologie, 9, 308.

Burch, G. E., Meyers, R., and Abildskov, J. A. (1954). A new electrocardiographic pattern observed in cerebrovascular accidents. Circulation, 9, 719.

Cropp, G. J., and Manning, G. W. (1960). Electrocardiographic changes simulating myocardial ischemia and infarction associated with spontaneous intracranial hemorrhage. Circulation, 22, 25.

Farrell, G. (1960). Adrenoglomerulotropin. Circulation, 21, 1009.

Hecht, H. H., and Anderson, R. B. (1947). The influence of dibenamine (N,N-dibenzyl- $\beta$-chloroethyl-amine) on certain functions of the sympathetic nervous system in man. Amer. J. Med., 3, 3.

Hegglin, R., and Holzmann, M. (1937). Elektrokardiographische Befunde beim Paragangliom der Nebenniere. Dtsch. Arch. klin. Med., 180, 681.

Hersch, C. (1961). Electrocardiographic changes in head injuries. Circulation, $23,853$.

Lepeschkin, E. (1951). Modern Electrocardiography, Vol. I. Williams and Wilkins, Baltimore.

(1955). Symposium on electrocardiography and vectorcardiography: The $U$ wave of the electrocardiogram. A.M.A. Arch. intern. Med., 96, 600.

Levine, H. D. (1953). Non-specificity of the electrocardiogram associated with coronary artery disease. Amer. J. Med., 15, 344.

Magida, M. G., and Roberts, K. E. (1953). Electrocardiographic alterations produced by an increase in plasma pH,

bicarbonate and sodium as compared with those seen with a decrease in potassium. Circulat. Res., 1, 214.
Marks, J. (1956). Central nervous system influence on the genesis of atrial fibrillation. Ohio St. med. J., 52, 1054. 
Paulian, D., Tudor, M., and Constantinesco, G. G. (1939). Les modifications de l'électrocardiogramme dans les tumeurs cérébrales. Arch. Neurol. (Paris), 3, 230.

Pool, J. L. (1957). Vasocardiac effects of the circle of Willis. A.M.A. Arch. Neurol. Psychiat., 78, 355.

Rosnowski, M. (1937). Influence de l'effort corporel sur le cœur chez les sportifs; étude électrocardiographique. Arch. Mal. Cour, 30, 133.

Schubart, A. F., Marriott, H. J. L., and Gorten, R. J. (1958). Isorhythmic dissociation. Amer. J. Med., $24,209$.

Sensenbach, W. (1946). Some common conditions, not due to primary heart disease, that may be associated with changes in the electrocardiogram. Ann. intern. Med., 25, 632.

Shuster, S. (1960). The electrocardiogram in subarachnoid hæmorrhage. Brit. Heart J., 22, 316.

Sokolow, M., and Lyon, P. B. (1949). The ventricular complex in left ventricular hypertrophy as obtained by unipolar precordial and limb leads. Amer. Heart J., 37, 161.

Storm van Leeuwen, W. (1945). Thesis, University of Leyden.

Tobin, J. L. (1956). Complications of meningococcus infection in a series of sixty-three consecutive sporadic cases. Amer. J. med. Sci., $231,241$.

Welt, L. G., Seldin, D. W., Nelson, W. P., German, W. J., and Peters, J. P. (1952). Role of the central nervous system in metabolism of electrolytes and water. Arch. intern. Med., 90, 355. 